\title{
ATYPICAL PNEUMONIAS IN CEYLONESE CHILDREN
}

\author{
BY \\ C. C. DE SILVA and G. H. COORAY \\ From the Departments of Paediatrics and Pathology, University of Ceylon
}

(Received for pUblication january 26, 1953)

\begin{abstract}
Although cases of primary non-bacterial pneumonia of unknown but probable viral origin have been reported from Europe and America only meagre references to this condition have been made in Indian medical literature. Shone and Passmore (1943) have referred to an outbreak of pneumonitis associated with autohaemagglutination in Indian army personnel. No such cases have yet been reported from the island of Ceylon. The purpose of this paper is to record nine cases which conform to the description of 'atypical' pneumonias reported by workers in other countries (Golden, 1944; Dingle, 1947; Parker, Jolliffe and Finland, 1947; Scadding, 1951).

The diagnosis of the first two cases was made at necropsy, and, as a result of these findings, subsequent cases, where the clinical picture differed from that of bacterial pneumonias, were carefully investigated, particular attention being paid to the estimation of cold agglutinins in the serum and to radiological changes in the lungs.
\end{abstract}

\section{- Clinical Features}

The main clinical features were not specific, and in the absence of other investigations the diagnosis might have been influenza, bronchitis or acute respiratory infections. The onset was insidious, usually with a cough, and the temperature ranged from $98 \cdot 4^{\circ} \mathrm{F}$. to $105^{\circ} \mathrm{F}$. The cough was not troublesome in most of the cases.

Physical signs consisted of râles and rhonchi of various tones, intensities and pitches, heard all over the lungs. The duration of the illness ranged from four to 144 days with an average of $28 \cdot 3$ days. If three very prolonged cases, lasting 39, 150 and 23 days respectively (the last complicated by meningitis) are excluded, the average period of illness is reduced to $7 \cdot 8$ days.

\section{Laboratory Investigations}

Lewcocyte Comt. Absence of a leucocytosis was a feature in all except two cases, but in all except one, sulphonamide drugs had been given before the count was done. In the one exception, a baby 3 months old, the total leucocytes were 17,600 per c.mm. in the first week of the illness, though the polymorphonuclears were only $31 \%$ and the lymphocytes $69 \%$.

Cold Agghtinins. In five out of six cases the titre ranged from 1 in 64 to 1 in 256; the sixth read 1 in 32. Although this child was resistant to all antibiotics, including aureomycin, the $\mathrm{x}$-ray appearances were suggestive of atypical pneumonia.

\section{Radiological Appearances}

Opacities were seen in all zones. In some cases, the shadows were limited to the upper zone (Fig. 1). In others they were mainly basal (Fig. 2), and in one the shadows were mainly hilar (Fig. 3). In the remaining cases opacities were seen in more than one zone. In one the opacities presented a honeycombed appearance (Fig. 2) in the right lung, the left lung being emphysematous.

The appearances described above are quite unlike those seen in segmental collapse, bronchial or lobar pneumonia. Although the appearance in Fig. 1 may

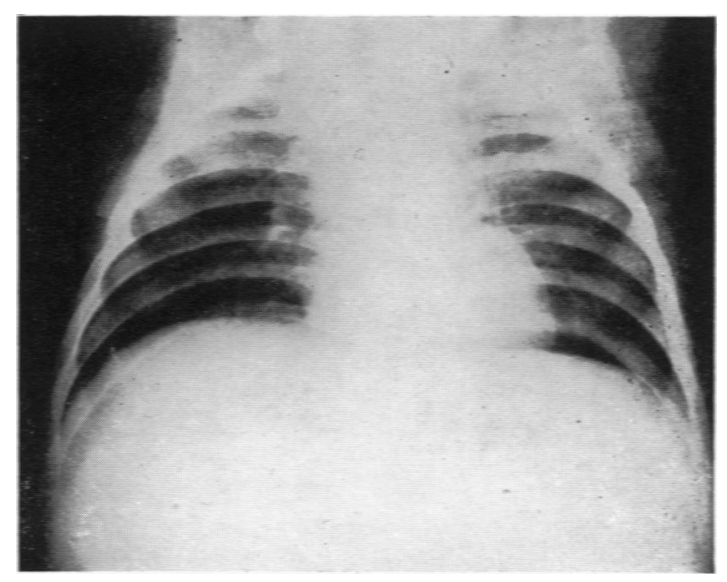

Fig. 1.-Bilateral apical opacities. 


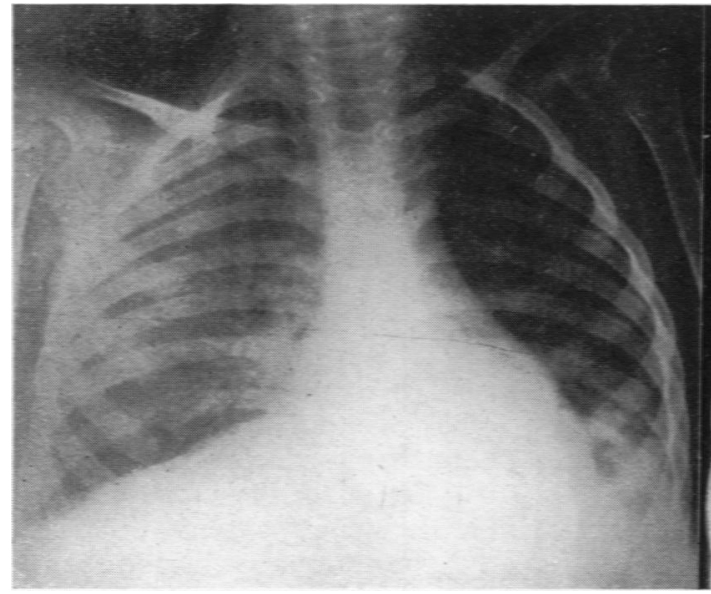

FiG. 2-Honeycombed appearance of opacities at base of right lung with emphysema of left lung.

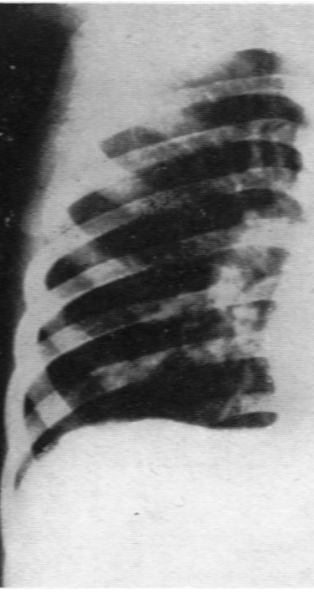

Fig. 3.-Hilar shadows.

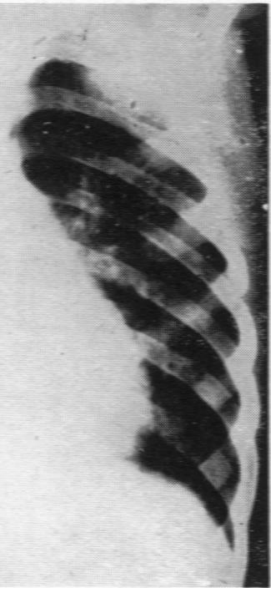

be -mistaken for bilateral upper lobe collapse, appearances at necropsy were those of atypical pneumonia.

\section{Diagnosis}

To a large extent the diagnosis was made by a process of exclusion. It soon became apparent that we were dealing with a type of pneumonia that did not respond to penicillin in the usual dramatic manner. Bronchial breathing and impairment of percussion note were conspicuous by their absence, although dyspnoea was a marked feature in many cases, especially at the onset of the illness. The temperature was remittent and came down gradually by lysis (Figs. 4 and 5). The diagnosis was confirmed by radiology and serologically by noting the presence of cold agglutinins in the serum.

\section{Progeosis}

There were four deaths in these nine cases, a higher mortality than in similar series published from other countries. Three deaths were in young infants. The poor nutritional state of our children may have been a deciding factor in the poor prognosis. The severe cases that ended fatally

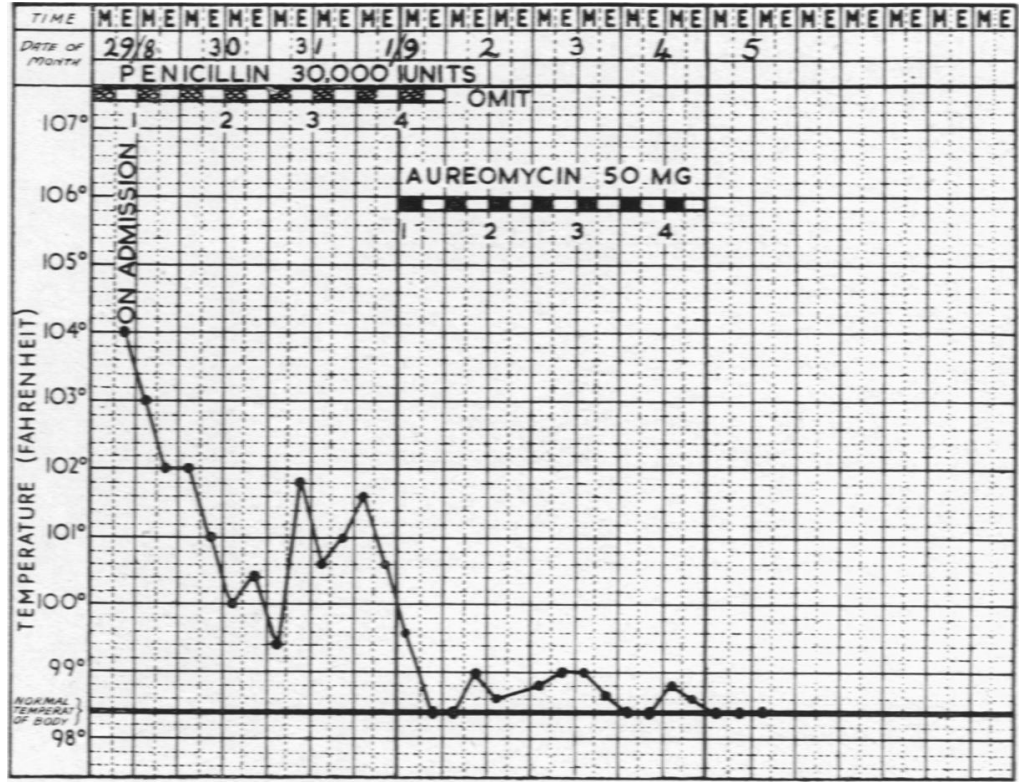

Fig. 4.-Temperature chart showing quick response to aureomycin. appeared to fall into a clinically related group with high fever, severe cough, marked dyspnoea, cyanosis, sweating and collapse without physical signs of consolidation or radiological evidence of pneumonia.

Treatment

Aureomycin was used in six cases when combined sulphadiazine and penicillin treatment had been found to be ineffective. In three cases the tempera- 


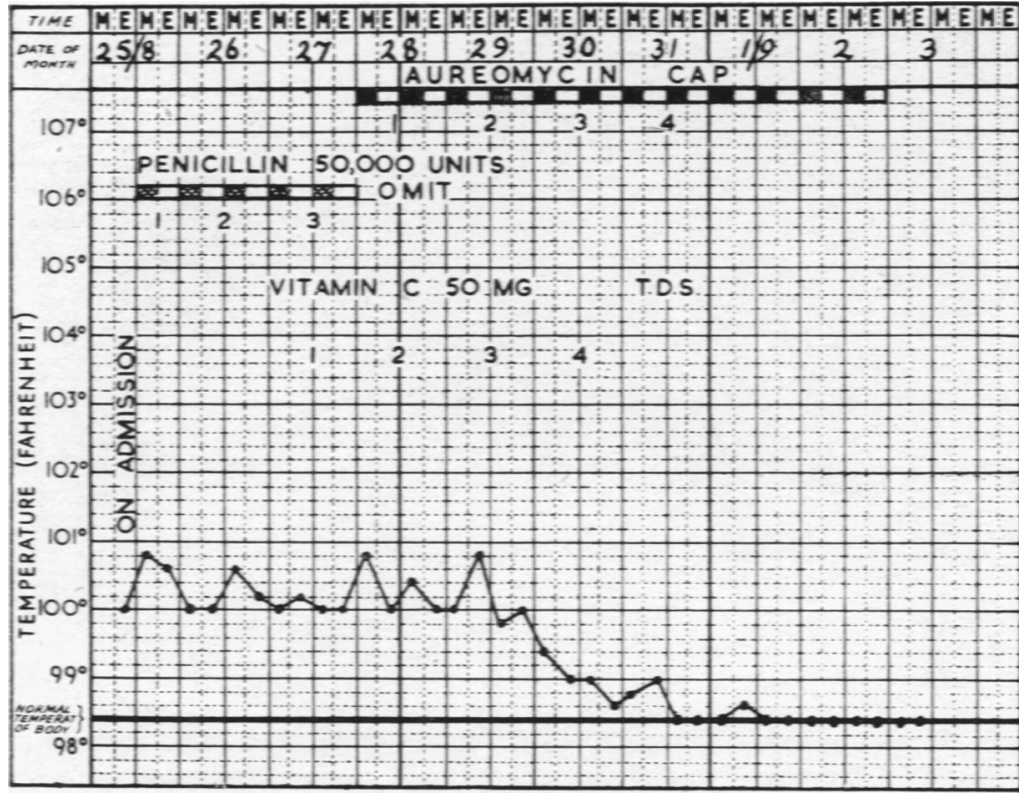

Fk. 5.-Temperature chart showing persistence of low fever in spite of penicillin. Temperature settled down after aureomycin. bronchi, near which the lung tissue was often haemorrhagic. The smaller bronchi stood out rather prominently and their walls appeared thickened. On squeezing the lung mucopurulent material was extruded from the bronchi.

Microscopic Appearances. The general appearance of a section is shown in Fig. 7. A marked degree of cellular infiltration was seen around the bronchioles, the cells spreading in the interstitial tissue of the lung for some distance. The perivascular spaces were prominent on account of oedema. Several such patches of peribronchial and interstitial, cellular infiltration separated by congested and oedematous lung were to be seen in a section. The cells around bronchioles as well as those in the alveolar septa were

ture settled down in 18, 24 and 60 hours respectively, and in two others only after six and 15 days respectively. The last ended fatally in spite of the drug. Three patients, who did not receive aureomycin, also died and in one the temperature settled although penicillin alone had been given, but the child succumbed to an attack of diarrhoea. Aureomycin was thus effective in only a few of our cases.

\section{Pathology}

Out of the four deaths permission for a necropsy was obtained in three. In our two earliest cases neither serological nor radiological examinations had been done, as we did not suspect that -atypical pneumonias occurred in this country. The necropsy findings were so unlike those of bacterial pneumonia and agreed in every detail with the pathological features of atypical pneumonia described by Golden (1944) that we investigated subsequent cases with considerable care. In the two latter deaths the diagnosis of atypical pneumonia had been made during life on serological and skiagraphic appearances, and confirmatory evidence was obtained at necropsy in one. In the other necropsy was not permitted.

Macroscopic Appearances. Although the pleura (Fig. 6) was smooth and glistening for the most part, the lungs showed focal lesions consisting of slightly raised, whitish areas distributed particularly around mononuclear (Figs. 8 and 9). The bronchiolaro lumina contained desquamated cells of the mucous? membrane and cellular debris. In some bronchioleso the entire mucous membrane was desquamated, but?

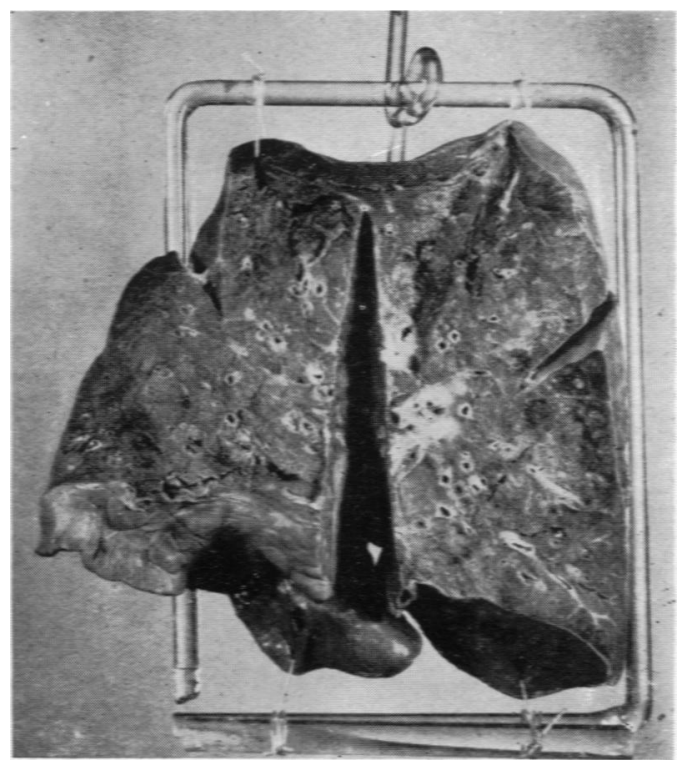

Fig. 6.-Hemisection of lung showing marked prominence of bronchioles due to peribronchiolitis. $\times \frac{1}{2}$. 


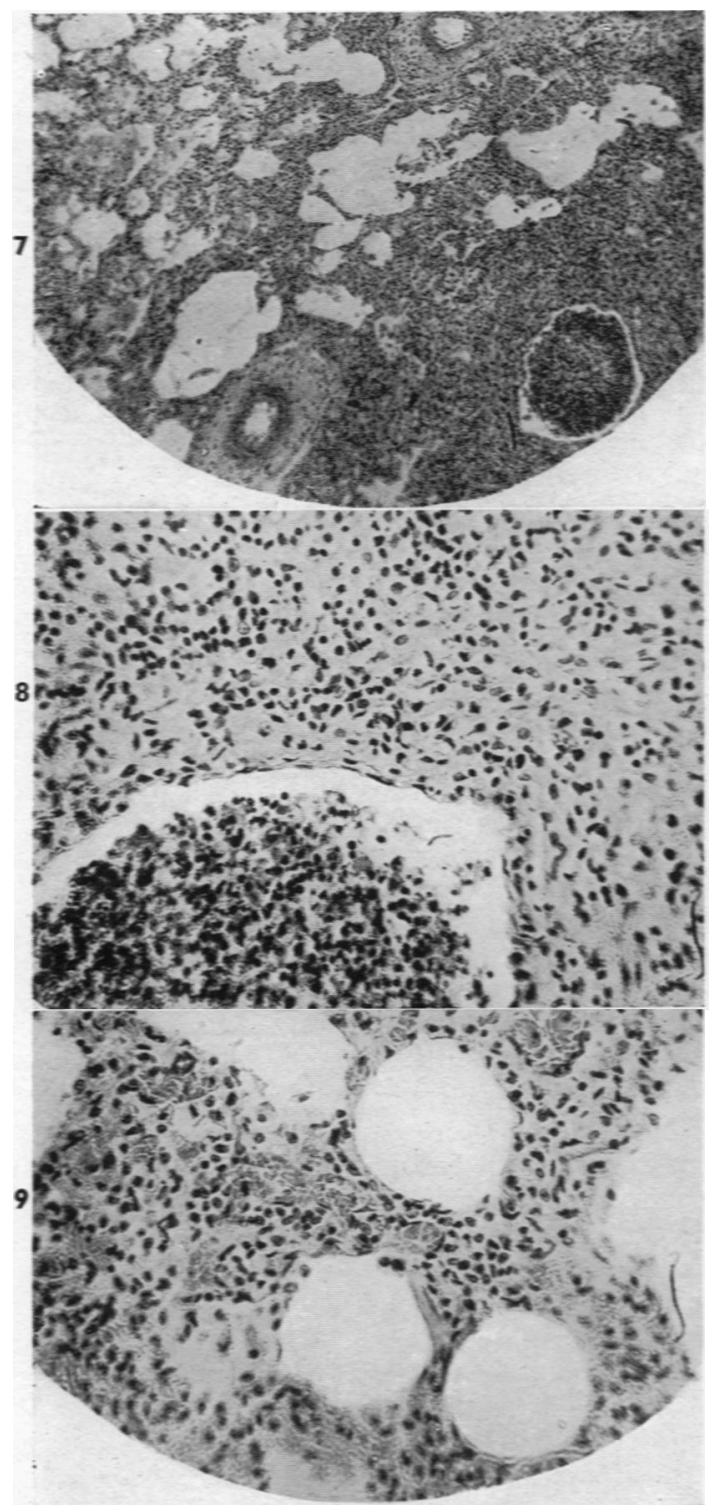

Frg. 7.-Low-power view of section showing a bronchiole containing cellular debris with marked peribronchiolar cell infiltration, and perivascular oedema. Haematoxylin and $\operatorname{cosin} \times 50$.

Fig. 8.-High-power view of Fig. 7 showing large numbers of mononuclear cells around a bronchiole the lumen of which contains desquamated cells and cellular debris. Haematoxylin and $\operatorname{cosin} \times 200$.

F1G. 9.-High-power view of Fig 7 showing alveolar septa heavily infiltrated with mononuclear cells. Note prominent capillaries in interstitial tissue and patent alveoli. Haematoxylin and cosin $\times 200$.

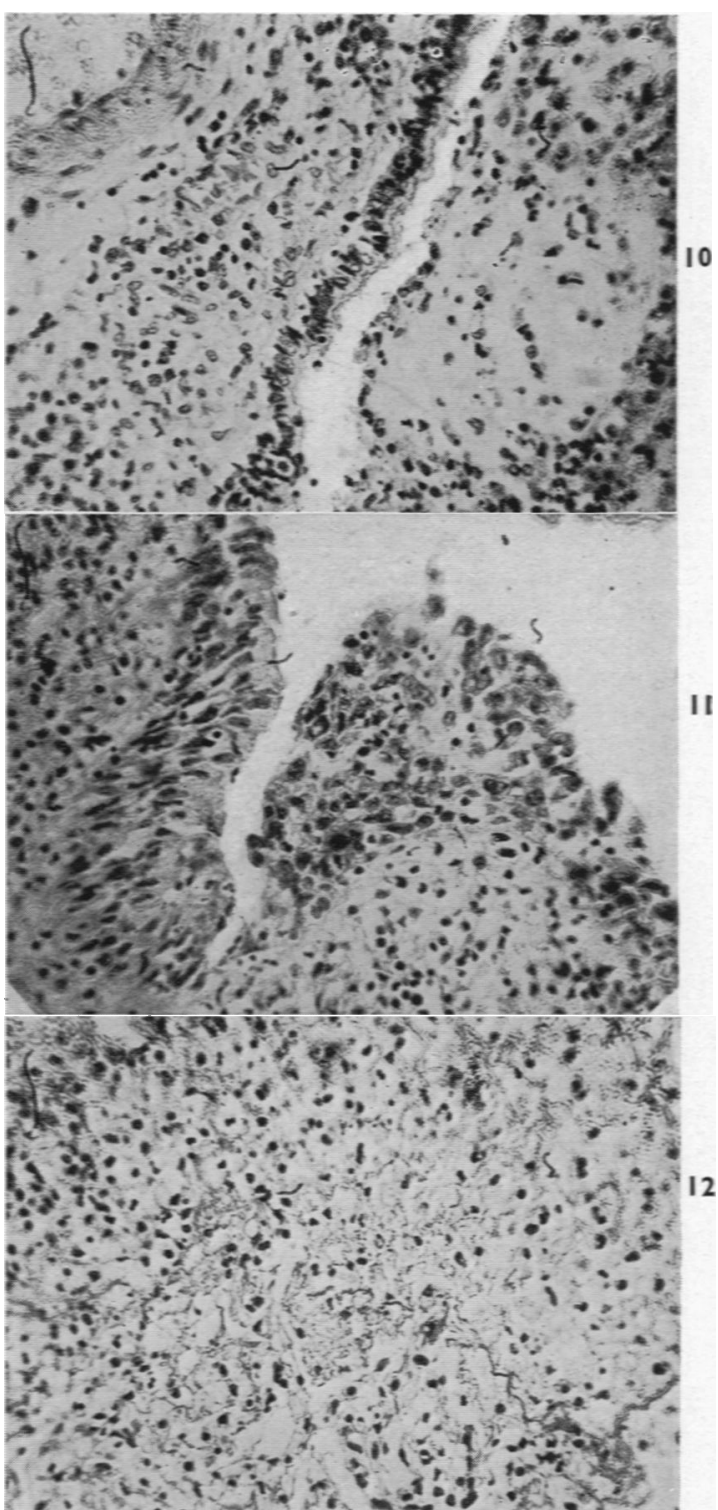

Fig. 10.-Intact mucous membrane of a larger bronchiole. Polymorphonuclear leucocytes suspended in mucoid material inside lumen.

Mononuclear cell infiltration in the peribronchial tissue. Haematoxylin and cosin $\times 200$.

Fig. 11.-Focus of squamous cell metaplasia. Haematoxylin and $\operatorname{cosin} \times 200$.

FG. 12.-Thread-like appearance of fibrin inside an alveolus. Weigert's fibrin stain $\times 200$. 
in others, particularly the larger ones, the mucosa was intact, the lumen being occupied by polymorphonuclear leucocytes suspended in mucoid material (Fig. 10). An occasional bronchiole showed metaplastic transformation of the lining to a squamous type of epithelium (Fig. 11). In contrast to the involvement of alveolar walls, the alveolar lumina contained air (Fig. 9). In some alveoli, however, there was fibrin which either filled the alveolar space or formed a layer on the alveolar wall. More often the fibrin appeared in the form of fine threads forming a network entangled in which were the nuclei of alveolar cells (Fig. 12).

\section{Discussion}

We have labelled the series reported here as 'atypical' pneumonias because we are of the opinion that they will probably be found on further investigation to be due to more than one aetiological factor, but clinically, serologically, radiologically and pathologically all of them are quite distinct from bacterial pneumonias.

It has to be decided whether the causative agent in this series is an ill-defined virus such as the one described by Eaton, Meikeljohn, VanHerick and Talbot (1942) as being responsible for the atypical pneumonias or whether it is one of the known infective agents such as the viruses of psittacosisornithosis or influenza, or a rickettsia ( $R$. burneti). Clinically and radiologically it is impossible to distinguish ornithosis from primary atypical pneumonia, but as the cold agglutination titre was fairly high in a large number of our cases (Morgan and Finland, 1948, have shown that it is usually negative in the former), we think it unlikely that the virus of psittacosis-ornithosis was the causative agent in this series.

Although it may be thought that some of these cases may have been due to the influenza virus, clinically they have not resembled influenzal pneumonia, a condition usually appearing in epidemics and characterized by cyanosis, a very high swinging temperature and a high mortality, and not by a high titre of cold agglutinins.

The evidence against our cases belonging to the $Q$ fever group ( $R$. burneti) is that, to our knowledge, $Q$ fever has not been reported in children but only in workers in abattoirs and laboratories and in military personnel. The cold agglutinins are also not increased in $\mathbf{Q}$ fever. Recently seven further children with atypical pneumonia have been investigated for agglutinins against $R$. burneti, with negative results.

Skiagraphic evidence and necropsy findings also support the view that we are dealing with atypical pneumonias probably of viral origin. Radiological appearances, similar to those we have described, have been reported by Parker et. al (1947) in a carefully investigated series of cases of primary atypical pneumonia. Moreover, the disappearance of the lung opacities in our cases after the administration of aureomycin when penicillin and sulpha drugs were ineffective, suggests that our cases may have been viral in origin. The naked eye appearances of the lungs at necropsy tally with the descriptions and illustration of Golden (1944), and the histological changes agree in every detail with his findings and those of Parker et al. (1947).

It is thus seen that our cases bear a close resemblance clinically, radiologically, serologically and pathologically to the primary atypical pneumonias described in other countries, but there are certain doubts about labelling them as such.

In the first place four of our nine patients died. Atypical pneumonia is generally reported as a mild disease with a negligible mortality but in two epidemics in Minneapolis Adams, Green, Evans and Beach (1942) reported a $20 \%$ mortality, and it is now widely accepted that primary atypical pneumonia is not entirely harmless in small infants. Three out of the four deaths in our series occurred in infancy. One of these though 14 months of age weighed only $12 \mathrm{lb}$; ; another, aged $4 \frac{1}{2}$ years, died within 24 hours of admission.

The second doubt is about our cold agglutination titres. Although Peterson, Ham and Finland (1943) and Turner (1943) suggested that an increase in cold agglutinins was peculiar to primary atypical pneumonia, Viswanathan and Natarajan (1945) have reported similar increases in tropical eosinophilia. However, none of our cases showed an eosinophilia or suffered from such conditions as trypanosomiasis, hepatic cirrhosis, paroxysmal haemoglobinuria or haemolytic anaemia, where too, the cold agglutinins are said to be increased. As Horsfall (1946) claimed that $8.1 \%$ of 209 normal subjects showed increased titres of over 1 in 40 , we investigated 81 cases at random for cold agglutinins.

Of 16 cases diagnosed as atypical pneumonia radiologically (only six are included in this series), nine $(56 \%)$ showed a titre of 1 in 64 or over. Of 65 other cases which included eosinophilia, haemolytic anaemias and various types of respiratory infections, e.g. bronchitis, bronchiolitis, bronchopneumonia, bronchiectasis, lung abscess, pulmonary tuberculosis, tuberculous meningitis, diarrhoea, malnutrition, nephritis and congenital heart disease, only three cases $(5 \%)$ showed a titre of 1 in 64 or over. We have not found it possible to carry out the 
other serological test (the streptococcus M.G. titre) which has been used in the diagnosis of atypical pneumonia. However, as this titre is increased in only $30 \%$ of the cases, we have considered the cold agglutinin test, which is increased in over $50 \%$, of greater value.

Robertson and Morle (1951) explain what they call the primary atypical pneumonia syndrome as being due to a segmental aspiration pneumonia. They doubt its viral origin and are of the opinion that it results from aspiration of products from an associated upper respiratory tract infection. They conclude: 'Our experience with this series of cases has led us to believe that the name and diagnosis "primary atypical pneumonia" is meaningless, as it is not a specific condition but merely represents a segmental aspiration pneumonia'. The evidence presented in this paper, particularly the skiagraphic appearances and the necropsy findings of a definite interstitial type of pneumonia with patent alveoli, is definitely against this condition being a segmental aspiration pneumonia. While we are willing to admit that some of the cases, particularly the milder ones in which penicillin appeared to be effective, may be examples of aspiration pneumonia, we cannot agree that all are of this nature.

\section{Summary}

The paper deals with nine cases, including four deaths, of atypical pneumonia occurring in Ceylonese children. The clinical features, laboratory findings, radiological appearances, treatment and pathological findings are described, and it is concluded that the illness, although not necessarily of uniform origin, differs from bacterial pneumonia, ornithosis, influenza and $Q$ fever.

We thank Professor W. A. E. Karunaratne, Professor of Pathology, University of Ceylon, for facilities, Dr. O. C. Raffel for general assistance. Messrs. K. M. M. Michael and P. Le Motte for the photographs, and Messrs. Justin de Silva, P. D. S. Amerasekera, G. A. H. Jayaweera and J. Fernando for technical assistance.

\section{REFERENCES}

Adams, J. M., Green, R. G., Evans, C. A. and Beach, N. (1942) J. Pediat., 20, 405.

Dingle, J. H. (1947). Advanc. Pediat., 2, 194.

Eaton, M. D., Meikeljohn, G., VanHerick, W. and Talbot, J. C. (1942). Science, 96, 518.

Golden, A. (1944). Arch. Path., Chicago, 38, 187

Golden A.

Horstall, F. L. (1946). N. Y. St.

Morgan, H. R. and Finland, M. (1948). Amer. J. clin. Path., 18. 593.
Parker, F., Jolliffe, L. S. and Finland, M. (1947). Arch. Path., Chicago 4 , 581 .

Peterson, O. L., Ham, T. H. and Finland, M. (1943). Science, 97,167

Robertson, P. W. and Morke, K. D. F. (1951). Brit. med. J., 2994.

Scadding J G (1951). Proc roy. Soc. Med 44 511.

Shone, S. and Passmore, R. (1943). Lancet, 2445.

Turner, J. C. (1943). Nature, Lond., 151, 419.

Viswanathan, R. and Natarajan, B. (1945). Lancet, 1, 148. 